\title{
Editorial
}

\section{Aplicações da Epidemiologia}

\author{
doi: $10.5123 /$ S1679-49742015000100001
}

$\mathrm{N}$ este primeiro número de 2015, a Epidemiologia e Serviços de Saúde: revista do Sistema Único de Saúde do Brasil (RESS) inicia a publicação de uma nova série de artigos, denominada "Aplicações da epidemiologia". 0 artigo "Epidemiologia translacional: algumas considerações" inaugura a série. Trata-se de texto elaborado por Moyses Szklo, professor do Departamento de Epidemiologia da Johns Hopkins Bloomberg School of Public Health e da Universidade Federal do Rio de Janeiro (UFRJ), além de editor-chefe do periódico American Journal of Epidemiology.

A epidemiologia translacional (EpiTrans) é conceituada como um processo que culmina na aplicação das ferramentas da epidemiologia para a produção de evidências científicas relevantes à Saúde Pública, ou seja, voltadas ao planejamento de políticas, programas e ações na área. A EpiTrans distingue-se parcialmente da epidemiologia puramente acadêmica. Enquanto esta privilegia a utilização de medidas baseadas em diferenças absolutas, como o risco atribuível e a efetividade populacional (em condições reais), aquela emprega comumente medidas baseadas em diferenças relativas (razões) e privilegia a eficácia (em condições ideais). Outra diferença relaciona-se à abordagem do confundimento. Para a EpiTrans, o confundimento pode ser considerado útil na identificação de grupos de risco, embora seja considerado um viés nos estudos etiológicos da epidemiologia acadêmica. ${ }^{1}$

0 artigo em pauta não poderia ser mais propício para a inauguração da série "Aplicações da Epidemiologia" na RESS, uma vez que a EpiTrans possui absoluta afinidade com a missão da revista: difundir o conhecimento epidemiológico aplicável às ações de vigilância, de prevenção e de controle de doenças e agravos de interesse da Saúde Pública, visando ao aprimoramento dos serviços oferecidos pelo Sistema Único de Saúde (SUS).

Diversos aspectos do processo da EpiTrans são apresentados, exemplificados e discutidos, como os níveis de evidência, a análise de decisão, e a avaliação da homogeneidade ou heterogeneidade dos estudos e suas implicações no processo de decisão sobre a efetividade de intervenções. ${ }^{1}$

Ressalte-se, ademais, que os temas supracitados mantêm afinidade com a revisão sistemática, assunto de editorial ${ }^{2}$ e outra série publicada na RESS desde o primeiro número de $2014 .^{3-6}$ No presente número, é publicado 0 quinto artigo desta série, que aborda a avaliação da qualidade da evidência de revisões sistemáticas. ${ }^{7}$

As próximas edições da RESS serão compostas por novos artigos de ambas as séries, aprofundando outras questões relacionadas às revisões sistemáticas, com autoria de Maurício Gomes Pereira e Tais Freire Galvão, e aspectos conceituais e metodológicos da epidemiologia aplicada, com artigos de autores convidados. Os leitores da RESS podem esperar por outros bons estudos, os quais, como os que ora publicamos, nos instiguem ao uso e à interpretação das evidências epidemiológicas que subsidiem o processo decisório implicado no ciclo de vida (formulação, implementação e avaliação) de políticas, programas e intervenções em Saúde Pública.

Leila Posenato Garcia

Instituto de Pesquisa Econômica Aplicada, Diretoria de Estudos Setoriais, Brasília-DF, Brasil

Elisete Duarte

Ministério da Saúde, Secretaria de Vigilância em Saúde, Brasília-DF, Brasil

\section{Referências}

1. Szklo M. Epidemiologia translacional: algumas considerações. Epidemiol Serv Saude. 2015 jan-mar;24(1):163-174.

2. Garcia LP. Revisão sistemática da literatura e integridade na pesquisa. Epidemiol Serv Saude [Internet]. 2014 mar [citado 2015 fev 22];23(1):7-8. Disponível em: http://scielo.iec.pa.gov.br/scielo.php?script=sci_arttext\&pid=S1679$49742014000100001 \& \operatorname{lng}=\mathrm{pt}$ 
3. Galvão TF, Pereira MG. Revisões sistemáticas da literatura: passos para sua elaboração. Epidemiol Serv Saude [Internet]. 2014 mar [citado 2015 fev 22];23(1):183-184. Disponível em: http://scielo.iec.pa.gov.br/scielo. php?script=sci_arttext\&pid=\$1679-49742014000100018\&lng=pt

4. Pereira MG, Galvão TF. Etapas de busca e seleção de artigos em revisões sistemáticas da literatura. Epidemiol Serv Saude [Internet]. 2014 jun [citado 2015 fev 22];23(2):369-71. Disponível em: http://scielo.iec.pa.gov.br/scielo. php?script=sci_arttext\&pid=S1679-49742014000200019\&lng=pt

5. Pereira MG, Galvão TF. Extração, avaliação da qualidade e síntese dos dados para revisão sistemática. Epidemiol Serv Saude [Internet]. 2014 set [citado 2015 fev 22];23(3):577-8. Disponível em: http://scielo.iec.pa.gov.br/scielo. php?script=sci_arttext\&pid=S1679-49742014000300021\&lng=pt

6. Pereira MG, Galvão TF. Heterogeneidade e viés de publicação em revisões sistemáticas. Epidemiol Serv Saude [Internet]. $2014 \mathrm{dez}$ [citado 2015 fev 22];23(4):775-8. Disponível em: http://scielo.iec.pa.gov.br/scielo. php?script=sci_arttext\&pid=S1679-49742014000400021\&lng=pt

7. Pereira MG, Galvão TF. Avaliação da qualidade da evidência de revisões sistemáticas. Epidemiol Serv Saude. 2015, jan$\operatorname{mar} ; 24(1): 173-175$. 